\title{
Selective Sensing of Metalloproteins from Non-selective Binding using a Fluorogenic Amphiphilic Polymer
}

\author{
Britto S. Sandanaraj, Robert Demont, Sivakumar V. Aathimanikandan, Elamprakash N. \\ Savariar, and S. Thayumanavan \\ Department of Chemistry, University of Massachusetts, Amherst MA 01003
}

Development of new biosensors for the detection of proteins is an active area of research due to their implications in proteomics, medical diagnostics, and pathogen detection. ${ }^{1}$ Designing artificial scaffolds has been of interest, because of their inherently robust characteristics suitable for device fabrication. Conjugated polyelectrolytes have received particular attention for sensing proteins, due to their water soluble and fluorescent properties. 2,3 More specifically, the possibility of energy or electron transfer from the polymer to the biological analyte resulting in a fluorescence change renders conjugated polymers useful for sensing metalloproteins. However, it has been shown through a set of careful experiments that such a change in fluorescence behavior could also be achieved through binding of non-metalloproteins. ${ }^{4}$ The planarization/deplanarization of the conjugated polyelectrolyte backbone upon interaction with the target analyte results in the chromic change of the polymer. ${ }^{5}$ We conceived that covalent incorporation of a fluorophore in a non-conjugated amphiphilic homopolymer nanoassembly, introduced by us in the literature recently, ${ }^{6}$ provides a unique solution to circumvent this issue: (i) the polymers form micelle-type assemblies with sizes of about $40 \mathrm{~nm}$ and afford optically clear assemblies in water. (ii) The proximity of the hydrophobic fluorophore to the solventexposed, carboxylate units to which the proteins bind should aid efficient energy or electron transfer events. (iii) Since any possible conformational change associated with the binding event is unlikely to change the inherent fluorescent characteristics of a pendant chromophore, the response will be specific to metalloproteins. With these characteristics, we hypothesized that even if the polymers non-specifically bind to the positively charged surface of the proteins, response in terms of a fluorescence change will occur only with proteins that contain the appropriate energy or electron donating/accepting functionalities, i.e. metalloprotein cofactor. We disclose here that our polymer was indeed selective in its fluorescence response to metalloproteins.

The structure of our target polymer is represented by 4 in Scheme $1 .^{7}$ Polymer 4 is designed so that the hydrophobic fluorescent anthracene present at the core of the nanoparticle 6 will act as a transducer for sensing, whereas the carboxylate groups presented at the solvent-exposed periphery of the assembly act as ligands for protein binding. The absorption and emission spectrum of polymer $\mathbf{4}$ reveals that the anthracene functionality is efficiently incorporated on to the polymer backbone and that the incorporation in to the polymer or the aggregation in water does not alter the inherent electronic properties of the anthracene moiety. ${ }^{7}$ Ability of the polymer 4 to sense proteins was studied by analyzing the change in the anthracene emission with increasing concentration of the protein.

e-mail: thai@chem.umass.edu.

Supporting Information Available: Detailed procedure for the synthesis of monomers and polymer and fluorescence spectra of polymer 4 with different proteins (PDF). This material is available free of charge via the Internet at http://pubs.acs.org. 
To test our hypothesis regarding the selective response to metalloproteins, we compared the fluorescence response of polymer $\mathbf{4}$ to cytochrome-c (Cc, a metalloprotein) and lysozyme (a non-metalloprotein). The results are shown in Figure 1a and $1 \mathrm{~b}$. It is clear that the fluorescence from the anthracene moiety in $\mathbf{4}$ reduced with the increasing concentration of cytochrome-c, while addition of similar concentrations of lysozyme to the solution had no effect on anthracene fluorescence. The pIs of cytochrome-c and lysozyme are 10.2 and 11.0, respectively. Therefore, we assumed that the nature of the interaction of our amphiphilic polymer assembly with these two proteins would be similar. The fluorescence decrease occurs with cytochrome-c, since the porphyrin functionality in this protein is capable of quenching the excited state of anthracene by energy or electron transfer. However, lysozyme does not have a photoactive or electroactive functionality to access anthracene's excited state energy.

The concentration-dependent quenching was used to generate a Stern-Volmer plot (Figure 1b). The slope obtained from the plot of the concentration of the protein $v s$. the ratio of fluorescent peak intensities $\left(\mathrm{I}_{0} / \mathrm{I}\right)$ is the Stern-Volmer quenching constant $\left(\mathrm{K}_{\mathrm{SV}}\right)$. For cytochrome-c, this value was $2.0 \times 10^{5}$. The higher value of $\mathrm{K}_{\mathrm{SV}}$ and the nonlinear behavior indicates a bindinginduced fluorescence quenching, i.e. a static quenching.

To test the generality of this sensing mode, we tested the fluorescent response of polymer 4 in water to twelve different proteins (Figure 2). Four of these proteins are metalloproteins, while the other 8 proteins are non-metalloproteins. Independent of the $\mathrm{pI}$ of the protein, none of the non-metalloproteins affect fluorescence changes in the polymer and thus shows a $\mathrm{K}_{\mathrm{SV}}$ value is close to zero (Figure 2). On the other hand, all metalloproteins exhibited $\mathrm{K}_{\mathrm{SV}}$ values ranging from $10^{4}$ to $10^{6}$, illustrating the selective response of our non-conjugated, fluorescent polymer to metalloproteins. We have shown that polymers of type $\mathbf{4}$ can bind to proteins such as chymotrypsin. ${ }^{8}$ Therefore, it is clear that the selectivity is in the response and not in binding. It is important to recognize that the $\mathrm{K}_{\mathrm{SV}}$ value itself represents not only the binding affinity of the metalloproteins with the polymer, but also the relative ability of the protein to quench the excited state of anthracene. For example, ferritin exhibits the highest $\mathrm{K}_{\mathrm{SV}}$; this is likely to be due to the fact that a single protein binding event brings hundreds of bound $\mathrm{Fe}^{2+}$, the key electron-accepting functionality, close to the otherwise fluorescent anthracene moiety. On the other hand, the greater $\mathrm{K}_{\mathrm{SV}}$ of cytochrome-c, compared to cytochrome-c-peroxidase $(\mathrm{CcP})$ and myoglobin, could arise from the difference in binding affinities due to the differences in pI. Note however that $\mathrm{pI}$ alone is not a good indicator of binding abilities of a protein to a charged polymer surface. ${ }^{9}$ Moreover, this simple pI-dependent binding affinity explanation, and therefore an impact on $\mathrm{K}_{\mathrm{SV}}$, is complicated by the fact that shifts in electronic spectra of porphyrins are possible (and therefore change in redox potentials and energy accepting capabilities) upon biding to a species with complementarily charged surface. ${ }^{10}$

We were interested in identifying the possible modes of fluorescence quenching in these polymers. There are mainly two limiting mechanisms of fluorescence quenching: energy transfer and electron transfer. Among the metalloproteins studied, the mechanism of quenching for ferritin is likely to be based on electron-transfer, since there is no chromophore that could accept the excited state energy from anthracene. The other three proteins have porphyrin cofactors, the absorbance spectra of which overlap well with the emission spectra of anthracene. Therefore, a Förster-type energy transfer is possible. But, the redox potentials of these proteins are such that an electron transfer based quenching is also viable. Usually, the fluorescent emission from the energy acceptor upon exciting the energy donor is considered to be a clear evidence for energy transfer. However, in our case, such a distinction is difficult, since Fe-porphyrins are inherently poor fluorescent emitters.

To investigate whether both energy and electron transfer quenching is possible with this polymer, we have carried out the following model studies. We have shown before that our 
homopolymer-based polyelectrolyte assemblies are capable of binding small molecules with complementary charges. ${ }^{11}$ Methyl viologen $\left(\mathrm{MV}^{+2}\right)$ is a cationic molecule that can accept an electron from the excited state of anthracene, but does not have the possibility of accepting its energy. We found that $\mathrm{MV}^{+2}$ was able to quench the fluorescence of anthracene with a $\mathrm{K}_{\mathrm{SV}}$ of $9.3 \times 10^{3} \mathrm{M}^{-1}$ (Figure 3a). On the other hand, proflavin is a cationic dye, which has an absorption spectrum that overlaps perfectly with the emission spectrum of anthracene.

Therefore, the latter molecule can accept energy from anthracene. If this molecule does accept the energy, it should be observable through an emission from proflavin upon excitation of anthracene. Indeed, when anthracene was excited at $373 \mathrm{~nm}$, significant amount of fluorescence arose from proflavin with a concomitant decrease in fluorescence from anthracene (Figure $3 b$ ). Control experiments showed that directly exciting proflavin at $373 \mathrm{~nm}$, by itself, at the same concentration does not afford a significant fluorescence. The $\mathrm{K}_{\mathrm{SV}}$ value for this process was found to be $4.6 \times 10^{4} \mathrm{M}^{-1}$. These results suggest that both energy and electron transfer mechanisms could operate in this sensing event. We could not resolve which mechanism is dominant in the metalloprotein binding studies due to the inherent lack of fluorescence from protein cofactors; this will however be a focus of our studies using time-resolved spectroscopy.

In summary, we have shown that a non-conjugated, fluorescent, amphiphilic polymer can recognize proteins non-specifically, but respond only to metalloproteins. The reason for this selective response is that: $(i)$ the cofactors in metalloproteins can quench the excited state of the fluorescent polymer by an energy or an electron transfer process. (ii) There are no complications that arise from fluorescence response to binding-induced conformational changes. While these polymers are selective to metalloproteins, these are not specific to a particular metalloprotein at this time. Designing amphiphilic polymer surfaces that exhibit such features is a part of the ongoing efforts in our laboratories.

\section{Supplementary Material}

Refer to Web version on PubMed Central for supplementary material.

\section{Acknowledgment}

The authors thank the National Institute of Health (GM-65255) and the NSF-supported Center Hierarchical Manufacturing for financial support of this research.

\section{References}

1. a Kodadek T. Chem. Biol 2001;8:105-115. [PubMed: 11251285] b Wang D, Gong X, Heeger PS, Rininsland F, Bazan GC, Heeger AJ. Proc. Natl. Acad. Sci. U.S.A 2002;99:49-53. [PubMed: 11756675] c Pinto MR, Schanze KS. Proc. Natl. Acad. Sci. U.S.A 2004;101:7505-7510. [PubMed: 15136727] d Wiskur SL, Ait-Haddou H, Lavigne JJ, Anslyn EV. Acc. Chem. Res 2001;34:963-972. [PubMed: 11747414] e McQuade DT, Pullen AE, Swager TM. Chem. Rev 2000;100:2537-2574. [PubMed: 11749295] f Wright AT, Anslyn EV. Chem. Soc. Rev 2006;35:14-28. [PubMed: 16365639] g Baldini L, Wilson AJ, Hong J, Hamilton AD. J. Am. Chem. Soc 2004;126:5656-5657. [PubMed: 15125644]

2. a Fan C, Plaxco KW, Heeger AJ. J. Am. Chem. Soc 2002;124:5642-5643. [PubMed: 12010029] b Wilson JN, Wang Y, Lavigne JJ, Bunz UHF. Chem. Commun 2003:1626-1627.

3. Chen L, McBranch DW, Wang H-L, Helgeson R, Wudl F, Whitten DG. Proc. Natl. Acad. Sci. U.S.A 1999;96:12287-12292. [PubMed: 10535914]

4. Kim I-B, Dunkhorst A, Bunz UHF. Langmuir 2005;21:7985-7989. [PubMed: 16089410]

5. Nelson TL, O'Sullivan C, Greene NT, Maynor MS, Lavigne JJ. J. Am. Chem. Soc 2006;128:56405641. [PubMed: 16637623]

6. Basu S, Vutukuri DR, Shyamroy S, Sandanaraj BS, Thayumanavan S. J. Am. Chem. Soc 2004;126:9890-9891. [PubMed: 15303841]

7. See supporting information for details. 
8. Sandanaraj BS, Vutukuri DR, Simard JM, Klaikherd A, Hong R, Rotello VM, Thayumanavan S. J. Am. Chem. Soc 2005;127:10693-10698. [PubMed: 16045357]

9. Renner C, Piehler J, Schrader T. J. Am. Chem. Soc 2006;128:620-628. [PubMed: 16402850]

10. Sanghera N, Pinheiro TJ. Protein Sci 2000;9:1194-1202. [PubMed: 10892811]

11. Basu S, Vutukuri DR, Thayumanavan S. J. Am. Chem. Soc 2006;127:16794-16795. [PubMed: 16316219] 


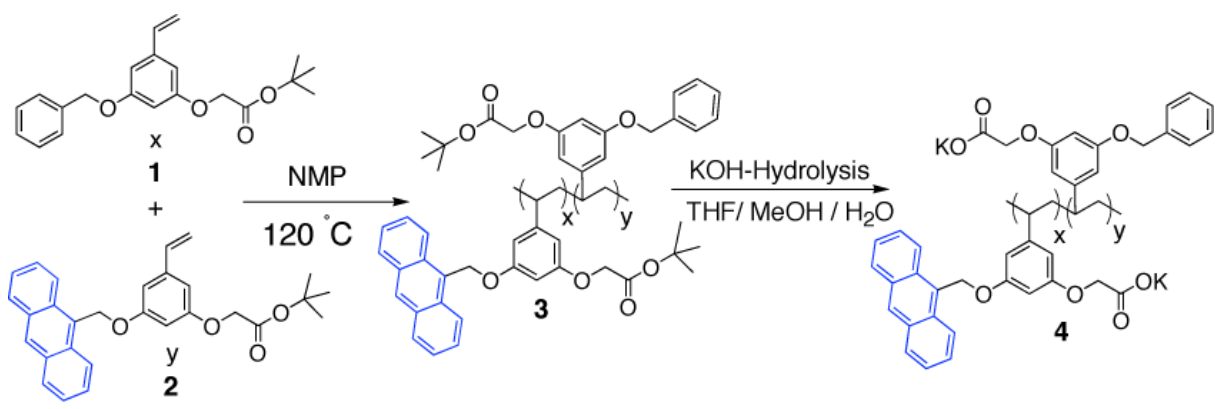

Scheme 1.

Synthesis of polymer 

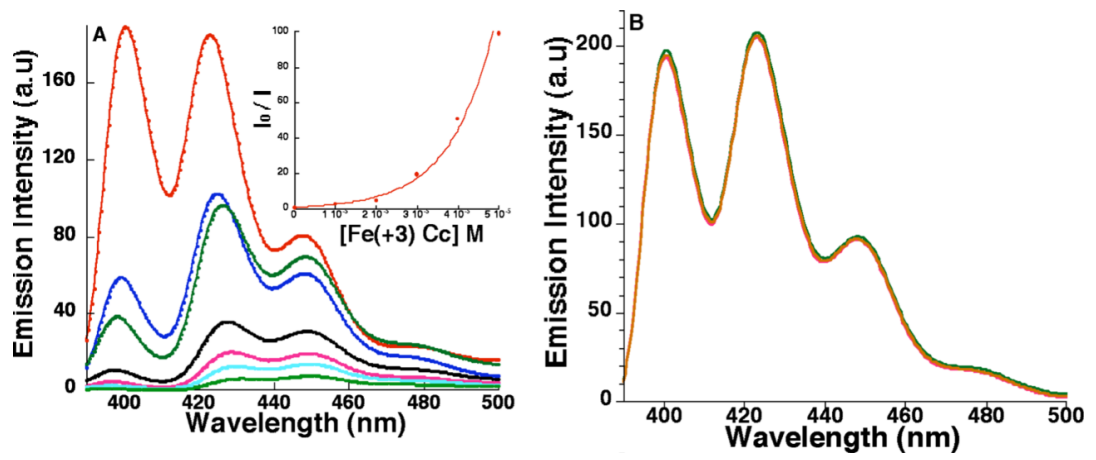

Figure 1.

(A) Fluorescence spectra of polymer 4 with various concentrations of metalloprotein (Cc) in $5 \mathrm{mM}$ sodium phosphate buffer (pH 7.4); ${ }^{7}$ (Inset) Stern-Volmer plot of the fluorescence spectra shown in panel A.; (B) Fluorescence spectra of polymer 4 with various concentrations of nonmetalloprotein (lysozyme). ${ }^{7}$ 


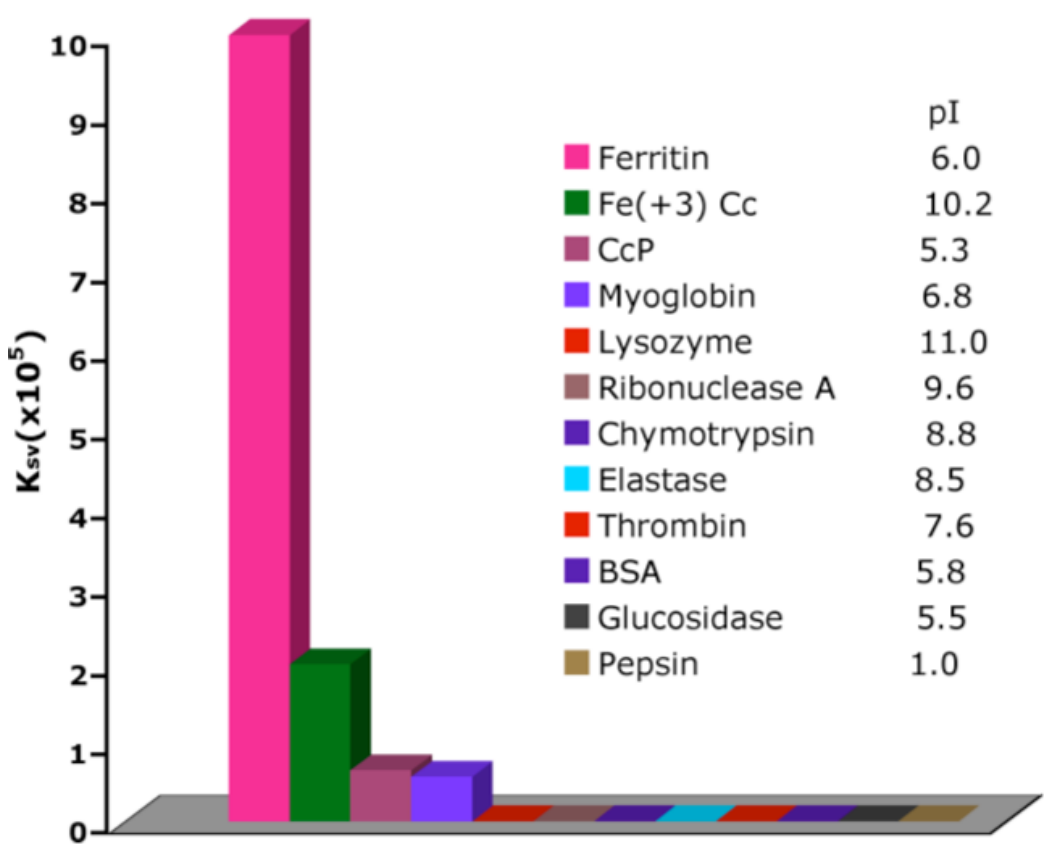

Figure 2.

$\mathrm{K}_{\mathrm{sv}}$ values of different proteins; ferritin $\left(\mathrm{K}_{\mathrm{sv}}=1.0 \times 10^{6}\right)$, Cc $\left(\mathrm{K}_{\mathrm{sv}}=2.0 \times 10^{5}\right)$, myoglobin $\left(\mathrm{Ksv}=5.7 \times 10^{4}\right), \mathrm{CcP}\left(\mathrm{K}_{\mathrm{sv}}=5.7 \times 10^{4}\right)$, all other non-metalloproteins $\left(\mathrm{K}_{\mathrm{sv}} \cong 0\right)$ 

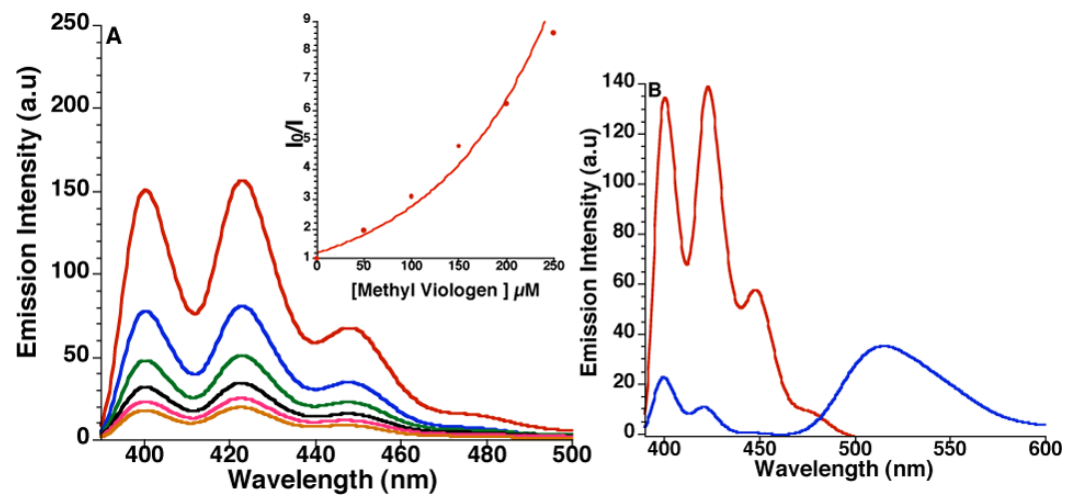

Figure 3.

(A) Fluorescence spectra of polymer $\mathbf{4}$ in the presence of various concentrations of methyl viologen ${ }^{7}$; (Inset) Stern-Volmer plot of the fluorescence spectra shown in panel A.; (C) Fluorescence spectra of polymer $\mathbf{4}$ in the absence (red line) and presence (blue line) of proflavin. 7 